\title{
Modeling self-heating and thixotropy phenomena under the cyclic loading of asphalt
}

Ebrahim Riahi $^{*}$ - Fatima Allou ${ }^{*}$ Ramon Botella ${ }^{* *}$ - Fateh Fakhari Tehrani ${ }^{*}$

- Frédéric Dubois ${ }^{*}$ - Joseph Absi*** - Christophe Petit ${ }^{*}$ - Felix E. PérezJiménez $^{* *}$

*Université de Limoges, GEMH, EA 3178, 19300 Egletons, France.

${ }^{* *}$ Universitat Politècnica de Catalunya - BarcelonaTech

${ }^{* * *}$ Université de Limoges, SPCTS, 87068 Limoges, France.

ebrahim.riahi@unilim.fr; fatima.allou@unilim.fr; ramon.botella@upc.edu;

fateh.fakhari-tehrani@unilim.fr; frederic.dubois@unilim.fr; joseph.absi@unilim.fr; christophe.petit@unilim.fr;.edmundo.perez@upc.edu 


\section{Modeling self-heating and thixotropy phenomena under the cyclic loading of asphalt mixes}

Asphalt concrete is a heterogeneous material containing a viscoelastic bituminous matrix and elastic aggregates. When testing asphalt materials under cyclic loading, various phenomena (so-called "biasing effects") can decrease the modulus. This effect has been explained by an increase in the temperature of materials due to energy dissipation (self-heating), thixotropy and damage. The aim of this study is to analyze a uniaxial cyclic tension-compression test performed on bitumen and asphalt mixes, in modeling self-heating as one of the biasing effects.

To quantify the self-heating and dissipated energy (as a heat source), a heterogeneous thermomechanical approach is introduced by separating the viscoelastic bituminous matrix from the elastic aggregates. According to this approach, various processes such as energy dissipation in the matrix due to viscoelastic properties, the thermal sensitivity of the matrix as well as its capacity to develop a heat source and diffuse heat through aggregates can all be studied. Local temperature variations are calculated by considering the heterogeneous dissipated energy field as a heat source. The complex modulus variation can then be calculated by taking into account both the temperature field and thermal sensitivity of the material. Simulation results show that as opposed to bitumen, in which $100 \%$ of complex modulus variations observed during a strain sweep test are due to self-heating, the results on asphalt mixes indicate that thixotropy varies with mechanical properties to a greater extent than self-heating. This fact is probably correlated with: a higher strain level in thin bituminous matrix films, a higher load velocity in thin matrix films, material heterogeneity, and the 3D characteristic of matrix loading during the tension-compression test on asphalt mixes.

Keywords: Heterogeneous simulation, Self-heating, Dissipated energy, Thixotropy, Viscoelasticity.

\section{Introduction}

Based on laboratory investigations and field observations, it has now been recognized that asphalt mixtures possess the capability to recover their mechanical properties, such 
as stiffness and strength, after being damaged under loading. The repetition of loading cycles on the material can lead to the occurrence of reversible phenomena influencing material properties, like self-heating, nonlinearity and, possibly, thixotropy (Di Benedetto, Nguyen and Sauzéat, 2011; Nguyen, Di Benedetto and Sauzéat, 2012). Under mechanical loading, the energy dissipated by viscoelastic behavior of the binder increases material temperature. This phenomenon (self-heating) has been demonstrated in several research projects by measuring sample temperature variations under cyclic loads for different material scales, e.g. bituminous binder (Bodin, Soenen and De La Roche, 2004), mastic (Van Rompu, Di Benedetto, Buannic, Gallet and Ruot, 2012; Van Rompu, Di Benedetto, Gauthier and Gallet, 2009) and asphalt concrete (Di Benedetto et al., 2011; Lundström, Ekblad and Isacsson, 2004; Mangiafico et al., 2015). Self-heating may be neglected for in situ loadings due to the available rest periods. However, during cyclic fatigue tests in the laboratory with a large number of loading cycles being applied to the sample over a short time period, self-heating cannot be neglected. Self-heating changes the mechanical properties of a viscoelastic material and is capable of explaining a portion of the reversible modulus decrease as the test is being carried out. Since this drop in modulus value is not caused by damage and alters the fatigue life estimation, self-heating is known as a biasing effect during fatigue testing. At present, the scientific community, including IUPAC (International Union of Pure and Applied Chemistry), generally agrees that thixotropy should be defined as: the continuous decrease in viscosity with time when flow is applied to a sample that has been previously at rest, and the subsequent recovery of viscosity over time when flow discontinues. The basic premises of this definition are: 1) its reliance on viscosity; 2) its implication of a time-dependent decrease in viscosity induced by flow; and 3) the reversibility of the effect when flow is either decreased or arrested. The rheological 
behavior of thixotropic materials can be understood on the basis of a microstructure with a strong shear history dependence. This microstructure results from relatively weak attractive forces between particles; the weakness is sufficient for breaking to occur by mechanical loading (Mewis and Wagner, 2009). Several authors have studied the occurrence of thixotropy in bituminous materials (Di Benedetto et al., 2011; Mangiafico et al., 2015; Mouillet, De La Roche, Chailleux and Coussot, 2012; Nguyen et al., 2012; F.E. Pérez-Jiménez, Botella and Miró, 2012; Félix E. Pérez-Jiménez, Botella, Miró and Martínez, 2015; Shan, Tan, Underwood and Kim, 2011).

Most studies conducted on these phenomena have entailed fatigue tests carried out with a cyclic stress/strain-controlled loading at a predefined frequency and temperature interrupted by rest periods. Two main approaches were adopted when defining the number and length of rest periods, either by including multiple short periods between intermittent loading steps or by introducing a single longer period between two continuous loading phases (Canestrari, Virgili, Graziani and Stimilli, 2015; Mangiafico et al., 2015; F.E. Pérez-Jiménez et al., 2012; Félix E. Pérez-Jiménez et al., 2015). To quantify self-heating, numerical simulations have been run by considering the dissipated energy as a heat source (Banic et al., 2012; Bodin et al., 2004; Pichon, Boutaous, Méchin and Sautereau, 2012). In these works, the dissipated energy field is considered to be homogeneous across the sample. Such however is not the case for asphalt mixes, which are heterogeneous materials composed of aggregates and bituminous binder, featuring distinct mechanical and thermal properties. As a result of the contrast between bituminous binder and aggregate stiffness, caused by exposure to a mechanical load, the local strain level in thin binder films (between two aggregates) will exceed the global strain level (Bahia, Zhai, Bonnetti and Kose, 1999; Coleri and Harvey, 2013; Fakhari Tehrani, Absi, Allou and Petit, 2013a). Dissipated energy as a 
function of strain level will be greater at these locations as well and will create a heterogeneous heat source. The temperature field will therefore be influenced by the heterogeneity of the thermal properties and heat source.

In this paper, numerical simulations of both a homogeneous type (bituminous binder) and heterogeneous type (bituminous matrix/aggregates) are proposed in order to study self-heating during cyclic loading and the effect of self-heating on variations in the asphalt material modulus. An incremental thermomechanical calculation is introduced to consider the effect of temperature variation on the mechanical properties of both the bitumen and matrix (and, consequently, on the dissipated energy field). The heterogeneous dissipated energy field in the asphalt mix is determined as a function of local strain and stress in the bituminous matrix. The temperature variation is then calculated by considering dissipated energy as the heat source. This temperature variation alters the mechanical properties and results in dissipated energy changes. A comparison with experimental tests (strain sweep test on bitumen and strain-controlled test on asphalt mixes) was drawn so as to quantify the self-heating and thixotropy.

\section{Materials and test procedure}

To analyze the biasing effects occurring during fatigue tests, two asphalt materials were considered: a 40/50 penetration grade straight-run bitumen, and an asphalt mix BBSG 0/10 (French acronym for semi gap-graded asphalt concrete).

\section{Bitumen}

The test performed on bitumen B40/50 was evaluated using a cyclic tensioncompression test at a controlled strain mode (known as the "EBADE" test, after the Spanish acronym for a strain sweep test: “Ensayo de BArrido de DEformaciones”). This test was developed at the Road Research Laboratory of the Technical University of 
Catalonia (Botella, Pérez-Jiménez and Miró, 2012; F.E. Pérez-Jiménez et al., 2012;

Félix E. Pérez-Jiménez et al., 2015). The specimen was a cylinder 20 mm in diameter and $39.5 \mathrm{~mm}$ high. The test was carried out at $10^{\circ} \mathrm{C}$ and $10 \mathrm{~Hz}$. The procedure consisted of applying a sinusoidal displacement signal (tension-compression) to the specimen, in ascending order, in stages of 5,000 loading cycles.

During the first step, a $740 \mu \mathrm{m} / \mathrm{m}$ strain amplitude was applied, and every 5,000 cycles the strain amplitude was increased by $740 \mu \mathrm{m} / \mathrm{m}$ through the $5^{\text {th }}$ step. When the fifth step was completed (i.e. after 25,000 cycles), the strain amplitude was decreased stepby-step back to the initial value, i.e. the strain amplitude applied during the first step. This process was repeated twice, and the complex modulus decrease and recovery were both observed. To clarify this concept, Figure 4 shows the evolution in strain amplitude throughout the test.

\section{Asphalt mix}

Tests on the BBSG 0/10 mix were performed by Nguyen (Nguyen et al., 2012; Nguyen, 2011) with a tension-compression configuration on cylindrical samples (120 mm high, 75-mm diameter). The asphalt mix tested herein was defined as the combination of a 35/50 penetration grade asphalt bitumen and diorite aggregates with a continuous 0-10 mm granular size. The fatigue test procedure consisted of applying a tensioncompression cyclic loading to the specimen in controlled strain mode (strain amplitudes: $108 \mu \mathrm{m} / \mathrm{m}$ and $96 \mu \mathrm{m} / \mathrm{m}$ ) at a frequency of $10 \mathrm{~Hz}$. The temperatures imposed in the thermal chamber equaled $12.4^{\circ} \mathrm{C}$ and $21.4^{\circ} \mathrm{C}$. For every fatigue lag, 10,000 cycles were applied.

To measure the external surface temperature, a sensor was placed on the sample surface. The internal temperature was also measured; the thermocouple was inserted into the sample at a distance of $11 \mathrm{~mm}$ from the center. 


\section{Finite element model}

\section{Numerical algorithm}

The heterogeneous field of dissipated energy and its effect on local temperature variation in the bituminous materials were determined by considering the dissipated energy as a heat source in the self-heating phenomenon. Under a mechanical loading, the viscoelastic behavior of asphalt binder acts as the source of dissipated energy. Temperature variation however modifies mechanical properties and, consequently, the quantity of dissipated energy will change. This nonlinear aspect was resolved by developing a specific convergence algorithm. Moreover, the coupling between viscoelastic and thermal calculations was treated with a step-by-step resolution algorithm (Riahi et al., 2016).

In this incremental approach, the local temperature value at each geometric point has been used to determine the mechanical properties of the viscoelastic material at the beginning of the time increment. To perform this step, the shift function $a_{T}$ was calculated by implementing the Williams-Landel-Ferry Law (Ferry, 1980), as defined in Equation (1):

$$
\log \left(a_{T}\right)=\frac{-C_{1} \cdot\left(T-T_{r e f}\right)}{C_{2}+T-T_{r e f}}
$$

where $T_{\text {ref }}$ is the reference temperature, $T$ the temperature in the model, and $C_{1} C_{2}$ two fitting parameters. The complex modulus $E^{*}$ and angle phase $\varphi$ were calculated using the 2S2P1D model (Olard and Di Benedetto, 2003) presented in Equation (2):

$$
E^{*}=E_{o}+\frac{E_{\infty}-E_{o}}{1+\delta \cdot\left(i \omega \cdot a_{T}\right)^{-k}+\left(i \omega \cdot a_{T}\right)^{-h}+\left(i \omega \cdot a_{T} \cdot \beta\right)^{-1}}
$$


with $i$ being the complex number defined by $i^{2}=-1, \omega=2 \pi f$ the pulsation, $\delta, k, h$ and $\beta$ phenomenological parameters, and $E_{O}$ and $E_{\infty}$ instantaneous and differed elastic stiffness, respectively. The phase angle vs. temperature was deduced by calculating the argument of $E^{*}$. The stress amplitude distribution $\sigma_{A}$ was calculated by applying the displacement to the model and moreover was based on a complex modulus expression under cyclic loading, as defined in Equation (3):

$$
\left|E^{*}\right|=\frac{\sigma_{A}}{\varepsilon_{A}}
$$

where $\varepsilon_{A}$ denotes the strain amplitude. The dissipated energy density per cycle $D E D_{c}$ (i.e. the heat source) was then determined using Equation (4) and integrated into the heat transfer algorithm in order to define temperature variation in the geometry over the time increment.

$$
D E D_{C}=\pi \cdot \sigma_{A} \cdot \varepsilon_{A} \cdot \sin \varphi
$$

\section{Boundary conditions and loading}

Considering the problem symmetry and for purposes of saving computation time, only half the specimen height was simulated in 2D (Fig. 1a). For the bitumen however, the entire sample was modeled using a homogeneous simulation (Fig. 1b). Given the cylindrical geometry, an axisymmetric assumption was adopted. The vertical displacement of the lower side was blocked. The horizontal displacement of the upper side was also blocked to take into consideration the effect of gluing a sample to gaps in the test machine (Fig. 1). 

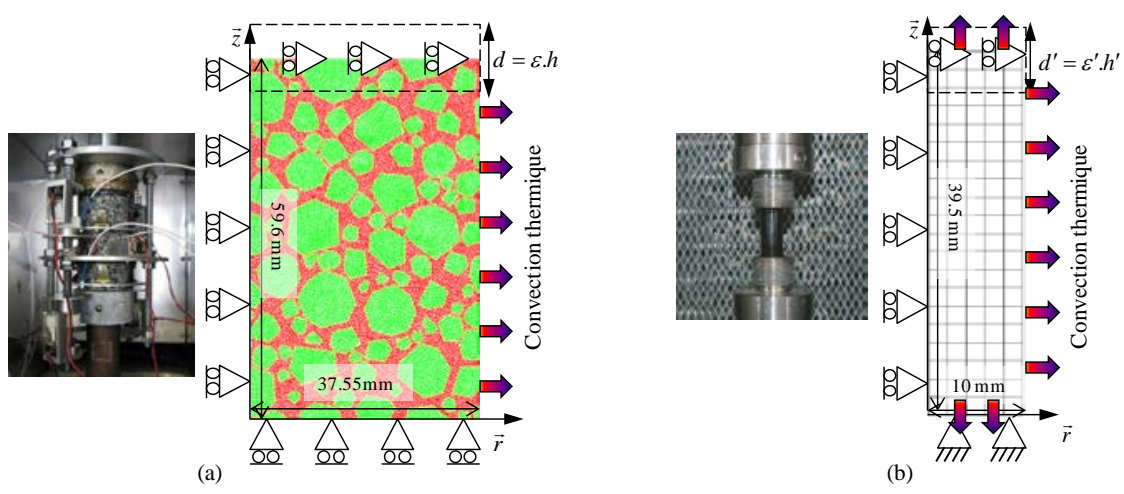

Figure 1: Numerical model and boundary conditions of: (a) the asphalt mix; (b) bitumen A vertical displacement generating the corresponding global strain amplitude of each charging cycle, as applied to samples during this experiment, was imposed on the upper side of the model. The heat transfer, via convection between the sample surface and air, was modeled on the vertical surface of the sample with a surface exchange coefficient equal to $32.8 \mathrm{~W} / \mathrm{m}^{2}{ }^{\circ} \mathrm{C}$ for the asphalt mix (Nguyen et al., 2012). For bitumen, the heat exchange with steel gaps was modeled as well by a surface exchange coefficient equal to $50 \mathrm{~W} / \mathrm{m}^{2} .{ }^{\circ} \mathrm{C}$ (Bodin et al., 2004).

\section{Heterogeneous Finite Element Mesh}

In this study, a random generation method was considered in respecting the gradation curve of aggregates using the MOA software (Fakhari Tehrani, Absi, Allou and Petit, 2013b). The model generated was meshed using isoparametric triangular elements and then implemented into the Castem software (“Cast3M”, 2013).

Due to the limitations of this MOA software in the percentage generation of inclusions, a 2-mm cutoff diameter was selected. Aggregates with a diameter of greater than $2 \mathrm{~mm}$ (2-10 $\mathrm{mm}$ ) were modeled in respecting their volume percentage in the final mixture. The aggregates with diameters smaller than $2 \mathrm{~mm}(0-2 \mathrm{~mm})$ were included in the matrix, thus producing a homogeneous phase of mortar sand for the matrix phase. Table 
1 indicates the volume percentage of mixture components. The bituminous matrix and aggregate cross-section are presented in Figure 2.

Aggregate (2-10 mm) Sand (0-2 mm) Binder Mortar sand

\begin{tabular}{ccccc}
\hline$\%$ & & & & \\
Volume & $57.4 \%$ & $28.6 \%$ & $14.0 \%$ & $42.6 \%$ \\
\hline
\end{tabular}

Table 1: Volumetric percentage of various mix components

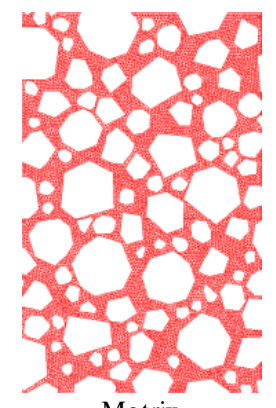

Matrix

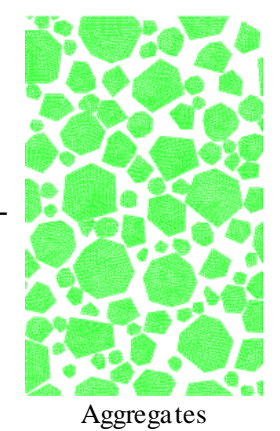

$=$

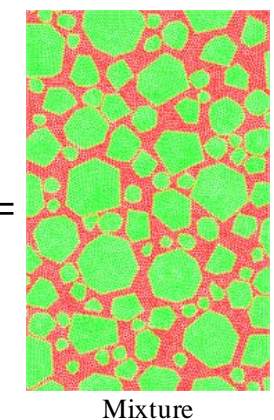

Figure 2: Biphasic Matrix/Aggregate cross-section mesh

\section{Thermal properties}

The thermal properties of diorite aggregates and bitumen have been extracted from the literature (Somé, Gaudefroy and Delaunay, 2013) and are listed in Table 2. For the asphalt mix, this matrix is a combination of sand $(0-2 \mathrm{~mm})$ and bitumen. Its thermal properties, in terms of conductivity, specific heat and density, have been calculated using the following mixing laws:

$$
\begin{gathered}
\lambda_{\text {matrix }}=\lambda_{\text {bitumen }} \frac{2 \lambda_{\text {bitumen }}+\lambda_{\text {Sand (0-2) }}-2 V_{\text {Sand (0-2) }}\left(\lambda_{\text {bitmen }}-\lambda_{\text {Sand (0-2) }}\right)}{2 \lambda_{\text {bitumen }}+\lambda_{\text {Sand (0-2) }}+V_{\text {Sand (0-2) }}\left(\lambda_{\text {bitumen }}-\lambda_{\text {Sand (0-2) }}\right)} \\
C p_{\text {matrix }}=\left(1-m_{\text {Sand (0-2) }}\right) \cdot C p_{\text {bitumen }}+m_{\text {Sand (0-2) }} \cdot C p_{\text {Sand (0-2) }}
\end{gathered}
$$




$$
\rho_{\text {matrix }}=\left(1-V_{\text {Sand }(0-2)}\right) \cdot \rho_{\text {bitumen }}+V_{\text {Sand }(0-2)} \cdot \rho_{\text {Sand }(0-2)}
$$

\begin{tabular}{lccc}
\cline { 2 - 4 } & $\begin{array}{c}\text { Conductivity } \\
\left(\mathrm{W} . \mathrm{m}^{-1} \cdot{ }^{\circ} \mathrm{C}^{-1}\right)\end{array}$ & $\begin{array}{c}\text { Specific heat } \\
\left(\mathrm{J} . \mathrm{kg}^{-1} \cdot{ }^{\circ} \mathrm{C}^{-1}\right)\end{array}$ & $\begin{array}{c}\text { Density } \\
\left(\mathrm{kg} / \mathrm{m}^{3}\right)\end{array}$ \\
\hline Bitumen & 0.162 & 1,560 & 1,030 \\
Sand-Aggregate & 2.59 & 650 & 2,750 \\
Matrix (Mortar sand) & 0.778 & 791 & 2,190 \\
\hline
\end{tabular}

Table 2: Thermal properties of components

\section{Mechanical properties}

The mechanical behavior of the granular structure was modeled in elastic behavior with a Young's modulus of $60 \mathrm{GPa}$ and a Poisson's ratio of 0.2 (Fakhari Tehrani et al., 2013b). For a mix, the 2S2P1D model parameters for the matrix (sand mortar) were fitted to the results of a complex modulus test conducted on the sand mortar derived by De La Roche (De La Roche, 1996). The 2S2P1D model parameters for the bitumen correspond to those reported by Olard (Olard, 2003). For a frequency of $10 \mathrm{~Hz}$, variations in the complex modulus and phase angle vs. temperature for the two materials are plotted in Figure 3.

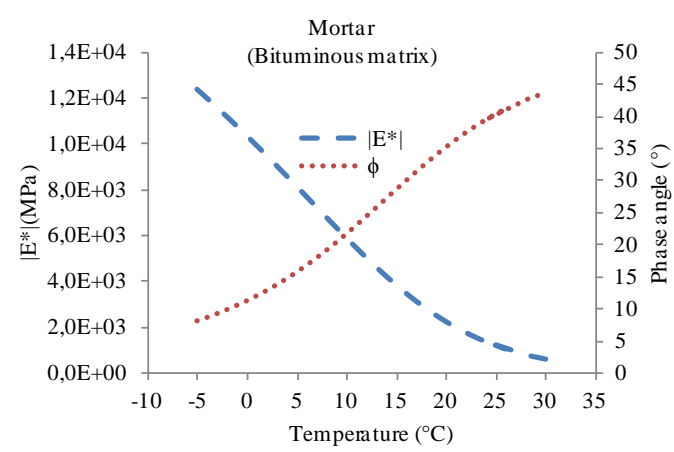

(a)

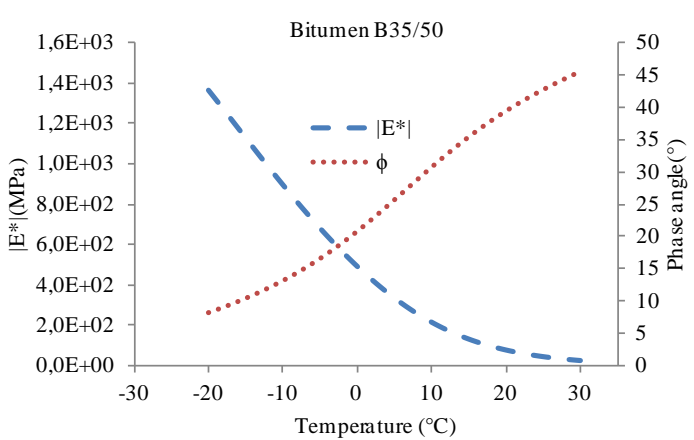

(b)

Figure 3: Modulus and phase angle master curves of bitumen and mortar at $10 \mathrm{~Hz}$ 


\section{Results}

\section{Bitumen}

Figure 4 shows a comparison of DEDc and complex modulus values measured and calculated at $10 \mathrm{~Hz}$ and $10^{\circ} \mathrm{C}$. It can be observed that the model is capable of predicting the variation in complex modulus and DEDc of the bitumen, with a good level of precision. The complex modulus of bitumen decreased as strain amplitude increased. However, once the strain amplitude started to decrease, the complex modulus returned to the same values as at the previous strain amplitude. Lastly, when the first strain step was once again reached, the complex modulus displayed the same value as at the beginning of the test.

The simulation results in terms of complex modulus and dissipated energy are presented in Figure 4. These results are in good agreement with experimental results and affirm that for these particular test conditions, the observed complex modulus loss with increasing strain was not caused by thixotropy, but instead by self-heating from the viscoelastic binder behavior. Let's note that self-heating in this test causes a maximum temperature variation of $4^{\circ} \mathrm{C}$ and $8^{\circ} \mathrm{C}$ respectively at the sample surface and center.
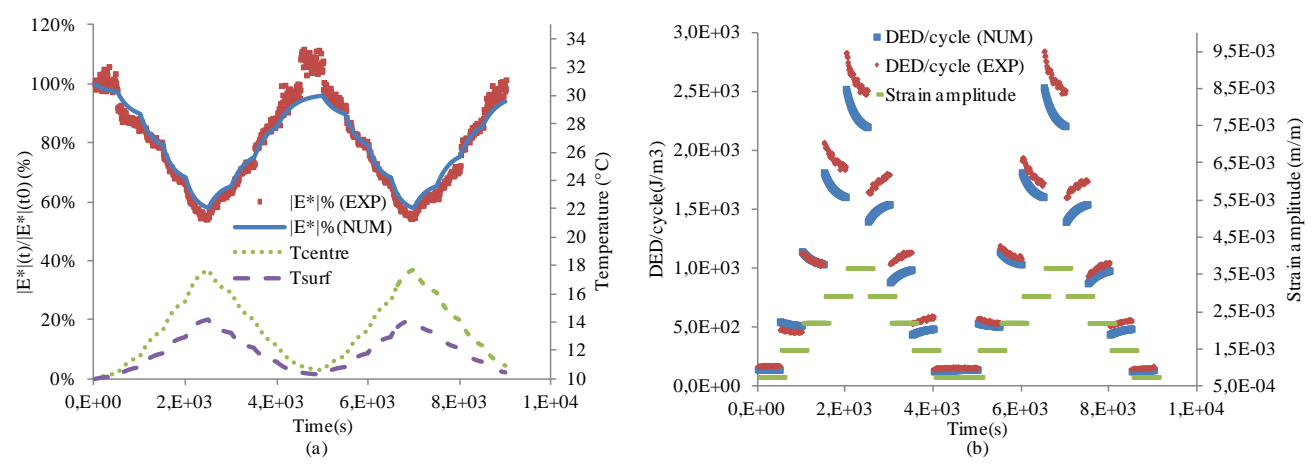

Figure 4: First up-and-down strain sweep test performed on B40/50 Complex modulus and dissipated energy density data

\section{Asphalt mix}

As the temperature evolved, the complex modulus of the mixture decreased over the 
course of the test. The variation in complex modulus of the mixture, as calculated by numerical simulation, was compared with experimental results for two different test temperatures $\left(12.4^{\circ}\right.$ and $\left.21.4^{\circ} \mathrm{C}\right)$. Figure 5 a presents the normalized variation of the complex modulus and temperature variation inside the sample for the test conducted at $12.4^{\circ} \mathrm{C}$ and $10 \mathrm{~Hz}$ with a strain amplitude of $108 \mu$ def.
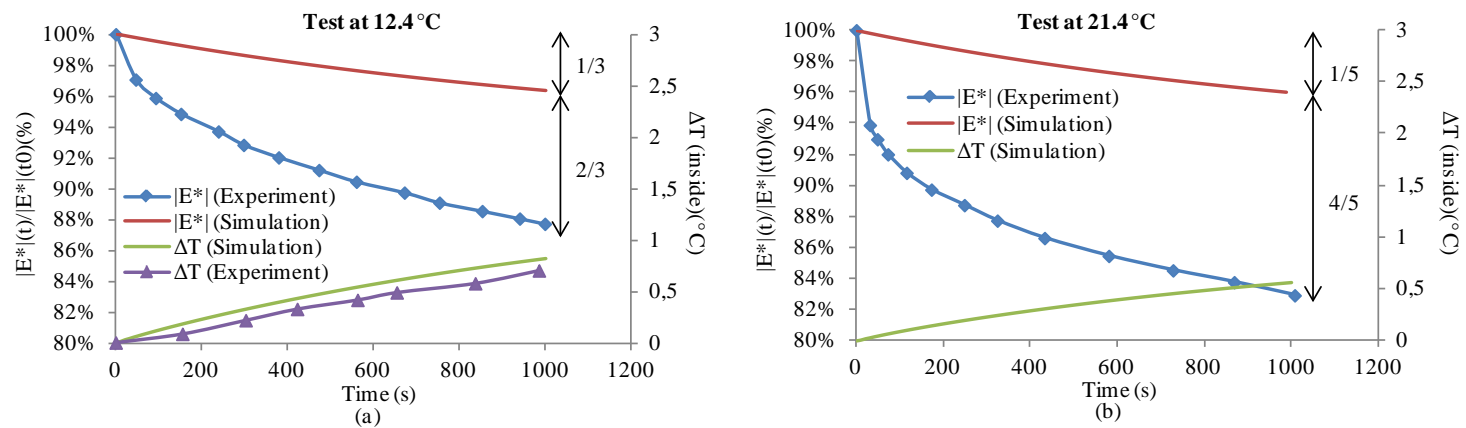

Figure 5: Normalized mixture complex modulus variation and temperature evolution:

(a) test temperature: $12.4^{\circ} \mathrm{C}$; (b) test temperature: $21.4^{\circ} \mathrm{C}$

Figure $5 \mathrm{~b}$ shows the results of the test performed at $21.4^{\circ} \mathrm{C}$ and $10 \mathrm{~Hz}$ with a strain amplitude of $96 \mu$ def. The complex modulus variation due to self-heating obtained by numerical simulation is compared with the experimental result for each test temperature. As opposed to the bitumen, Figure 5a indicates that self-heating of the mix can explain one-third of the total complex modulus decrease for the test conducted at $12.4^{\circ} \mathrm{C}$, while the remaining two-thirds are due to other biasing effects, such as thixotropy. For the test performed at $21.4^{\circ} \mathrm{C}$ (Fig. 5b), self-heating can explain one-fifth of the total modulus decrease with the rest being explained by other reversible phenomena (e.g. thixotropy). It can be concluded that the effect of thixotropy on a lower complex modulus value during the first phase of fatigue depends on material heterogeneity, thus causing a higher local strain level in the bituminous matrix.

\section{Conclusion}

This study has provided an innovative analysis to allow determining the true self- 
heating potential and global variation in the complex modulus of asphalt materials. The proposed approach has been based on a coupling of the thermo-viscoelastic model with the heat transfer process. Two asphalt materials (bitumen and an asphalt mix) were tested for purposes of this study.

For the test performed on bitumen, the complex modulus and DEDc predicted by the proposed model are in good agreement with experimental results. The results obtained show that the initial drop in complex modulus during the tension-compression test is not related to thixotropy, but rather to self-heating effects caused by viscoelastic energy dissipation.

For the asphalt mix, results show that self-heating appears to influence the complex modulus variation to a lesser extent than other biasing effects, namely thixotropy (33\% at $12^{\circ} \mathrm{C}, 20 \%$ at $21^{\circ} \mathrm{C}$ ).

Further investigations on bitumen are currently ongoing to validate the proposed analytical approach; these involve studies on various tests conditions like temperature, high strain level/high frequency and velocity, in order to evaluate the presence of other time/temperature-dependent phenomena capable of occurring along with the selfheating mechanism.

Other analytical approaches will be undertaken in the study of asphalt mixtures so as to verify the behavior of the same bituminous binder when interacting with the aggregate skeleton.

\section{References}

Bahia, H. U., Zhai, H., Bonnetti, K., \& Kose, S. (1999). Non-linear viscoelastic and fatigue properties of asphalt binders. Proceedings of the Association of Asphalt Paving Technologists, 68, 1-34. 
Banic, M., Stamenkovic, D., Miltenovic, V., Milosevic, M., Miltenovic, A., Djekic, P., \& Rackov, M. (2012). Prediction of heat generation in rubber or rubber-metal springs. Thermal Science, 16(suppl. 2), 527-539.

Bodin, D., Soenen, H., \& De La Roche, C. (2004). Temperature effects in binder fatique and healing tests. In 12-14 May (Ed.), 3rd Eurasphalt Eurobitume Congress (p. Book II Paper 136). Vienna, Austria.

Botella, R., Pérez-Jiménez, F. E., \& Miró, R. (2012). Application of a strain sweep test to assess fatigue behavior of asphalt binders. Construction and Building Materials.

Canestrari, F., Virgili, A., Graziani, A., \& Stimilli, A. (2015). Modeling and assessment of self-healing and thixotropy properties for modified binders. International Journal of Fatigue.

Cast3M. (2013). Http://www-cast3m.cea.fr/.

Coleri, E., \& Harvey, J. T. (2013). A fully heterogeneous viscoelastic finite element model for full-scale accelerated pavement testing. Construction and Building Materials, 43, 14-30.

De La Roche, C. (1996). Module de rigidité et comportement en fatigue des enrobés bitumineux . Ecole Centrale Paris.

Di Benedetto, H., Nguyen, Q. T., \& Sauzéat, C. (2011). Nonlinearity, Heating, Fatigue and Thixotropy during Cyclic Loading of Asphalt Mixtures. Road Materials and Pavement Design, 12(1), 129-158.

Fakhari Tehrani, F., Absi, J., Allou, F., \& Petit, C. (2013a). Heterogeneous numerical modeling of asphalt concrete through use of a biphasic approach: Porous matrix/inclusions. Computational Materials Science, 69, 186-196.

Fakhari Tehrani, F., Absi, J., Allou, F., \& Petit, C. (2013b). Investigation into the impact of the use of 2D/3D digital models on the numerical calculation of the bituminous composites’ complex modulus. Computational Materials Science, 79, 377-389.

Ferry, J. D. (1980). Viscoelastic Properties of Polymers. New York: Wiley.

Lundström, R., Ekblad, J., \& Isacsson, U. (2004). Influence of hysteretic heating on asphalt fatigue characterization. Journal of Testing and Evaluation, 32(6), 484493.

Mangiafico, S., Sauzéat, C., Di Benedetto, H., Pouget, S., Olard, F., \& Planque, L. (2015). Quantification of biasing effects during fatigue tests on asphalt mixes: 
non-linearity, self-heating and thixotropy. Road Materials and Pavement Design, $1-27$.

Mewis, J., \& Wagner, N. J. (2009). Thixotropy. Advances in Colloid and Interface Science, 147-148(C), 214-27.

Mouillet, V., De La Roche, C., Chailleux, E., \& Coussot, P. (2012). Thixotropic behaviour of paving grade bitumens under dynamic, 5th Eurasphalt \& Eurobitume Congress, June, Istanbul, 13-15.

Nguyen, Q. T. (2011). Comportement thermomécanique des enrobés bitumineux sous sollicitations cycliques dans les domaines linéaire et non-linéaire. $\mathrm{PhD}$ thesis. ENTPE de Lyon.

Nguyen, Q. T., Di Benedetto, H., \& Sauzéat, C. (2012). Determination of thermal properties of asphalt mixtures as another output from cyclic tension-compression test. Road Materials and Pavement Design, 13(1), 85-103.

Olard, F. (2003). Comportement thermomecanique des enrobes bitumineux a basse temperature : Relation entre les propriétés du liant et de l'enrobés. PhD thesis. ENTPE de Lyon.

Olard, F., \& Di Benedetto, H. (2003). General “2S2P1D” Model and Relation Between the Linear Viscoelastic Behaviours of Bituminous Binders and Mixes. Road Materials and Pavement Design, 4(2), 185-224.

Pérez-Jiménez, F. E., Botella, R., \& Miró, R. (2012). Differentiating between damage and thixotropy in asphalt binder's fatigue tests. Construction and Building Materials, 31, 212-219.

Pérez-Jiménez, F. E., Botella, R., Miró, R., \& Martínez, A. H. (2015). Analysis of the thixotropic behavior and the deterioration process of bitumen in fatigue tests. Construction and Building Materials, 101, 277-286.

Pichon, P. G., Boutaous, M., Méchin, F., \& Sautereau, H. (2012). Measurement and numerical simulation of the self heating of cross-linked segmented polyurethanes under cyclic loading. European Polymer Journal, 48(4), 684-695.

Riahi, E., Allou, F., Ulmet, L., Absi, J., Dubois, F., \& Petit, C. (2016). Numerical simulation of local temperature evolution in bituminous materials under cyclic loading. European Journal of Environmental and Civil Engineering.

Shan, L., Tan, Y., Underwood, B., \& Kim, Y. (2011). Separation of Thixotropy from Fatigue Process of Asphalt Binder. Transportation Research Record: Journal of the Transportation Research Board, 2207(2207), 89-98. 
Somé, S. C., Gaudefroy, V., \& Delaunay, D. (2013). A new laboratory method to evaluate the influence of aggregate temperature on the binder-aggregate bonding: first results. Materials and Structures, 47(6), 963-976.

Van Rompu, J., Di Benedetto, H., Buannic, M., Gallet, T., \& Ruot, C. (2012). New fatigue test on bituminous binders: Experimental results and modeling. Construction and Building Materials, 37, 197-208.

Van Rompu, J., Di Benedetto, H., Gauthier, G., \& Gallet, T. (2009). New fatigue test on bituminous binders and mastics using an annular shear rheometer prototype and waves propagation. In Lizos, M. Partl, T. Scarpas, \& I. Al-Qadi (Eds.), Advanced testing and characterisation of bituminous materials (pp. 69-79). Greece. 